\title{
Investigating relationships within the Index of Learning Styles: a data driven approach
}

\author{
Silvia Rita Viola*, Sabine Graf ${ }^{\dagger}$, Kinshuk$^{\ddagger}$ and Tommaso Leo* \\ *Dip. Ingegneria Informatica, Gestionale e dell'Automazione “Maurizio Panti", Universita' Politecnica delle \\ Marche, via delle Brecce Bianche, 60100 Ancona, Italy \\ Email: sr.viola@gmail.com, tommaso.leo@univpm.it \\ ${ }^{\dagger}$ Women's Postgraduate College for Internet Technologies, Vienna University of Technology, \\ Favoritenstrasse 9-11/E188-4, A-1040 Vienna, Austria \\ Email: graf@wit.tuwien.ac.at \\ ${ }^{\ddagger}$ School of Computing and Information Systems, Athabasca University, 1 University Drive, \\ Athabasca, Alberta T9S 3A3, Canada \\ Email: kinshuk@ieee.org
}

\begin{abstract}
Learning styles are incorporated more and more in e-education, mostly in order to provide adaptivity with respect to the learning styles of students. For identifying learning styles, at the present time questionnaires are widely used. While such questionnaires exist for most learning style models, their validity and reliability is an important issue and has to be investigated to guarantee that the questionnaire really assesses what the learning style theory aims at. In this paper, we focus on the Index of Learning Styles (ILS), a 44-item questionnaire to identify learning styles based on FelderSilverman learning style model. The aim of this paper is to analyse data gathered from ILS by a data-driven approach in order to investigate relationships within the learning styles. Results, obtained by Multiple Correspondence Analysis and cross-validated by correlation analysis, show the consistent dependencies between some learning styles and lead then to conclude for scarce validity of the ILS questionnaire. Some latent dimensions present in data, that are unexpected, are discussed. Results are then compared with the ones given by literature concerning validity and reliability of the ILS questionnaire. Both the results and the comparisons show the effectiveness of data-driven methods for patterns extraction even when unexpected dependencies are found and the importance of coherence and consistency of mathematical representation of data with respect to the methods selected for effective, precise and accurate modelling.
\end{abstract}

Keywords: Learning Styles, Felder-Silverman Learning Style Model, Data-Driven Approach, Data Mining, Student Models

\section{INTRODUCTION}

More and more research work is done on incorporating learning styles in e-education. For instance, learning styles have been analysed with respect to the behaviour of students in online courses (e.g., Graf \& Kinshuk, 2006b), and systems that provides adaptivity based on learning styles have been devel- 
oped such as $\mathrm{CS}_{3} 83$ (Carver, Howard \& Lane, 1999), IDEAL (Shang, Shi \& Chen, 20oI), MAS-PLANG (Peña, Marzo, and De la Rosa, 2002), and INSPIRE (Papanikolaou \& Grigoriadou, 2003).

For providing adaptivity regarding learning styles, the learning styles of the students have to be detected and recognized first. Recent research work is done on an approach to identify learning styles from the behaviour of students during an online course (Cha et al., 2006; García, Amandi, Schiaffino \& Campo, 2006; Graf \& Kinshuk, 2006a). Since these approaches are quite new and partially still under development, the most common and often used approach to identify learning styles is to let students fill out a questionnaire. For most learning style models, such a questionnaire exists. The validity and the reliability of such questionnaires are important issues and need to be proven. Also, it has been noticed that questionnaires have to deal with the problem that the given answers might not correspond to the real behaviour the questions aim to investigate, both intentionally and not intentionally (Draper, 1996). Therefore, investigations are necessary for detecting the coherence between the questionnaire's dimensions and the theoretical constructs they are aimed at assessing.

Several learning style models are presented in literature such as the model by Kolb (1984), Honey and Mumford (1982), and Felder and Silverman (1988). In this paper, we focus on the FelderSilverman learning style model (FSLSM) which is often used for providing adaptivity regarding learning styles in e-learning environments. FSLSM characterizes each learner according to four dimensions, each of them including 2 poles: active $(A)$ learners learn by trying things out and working with others whereas reflective $(R)$ learners learn by thinking things through and working alone. Sensing (Sen) learners like to learn concrete material and tend to be practical whereas intuitive (I) learners prefer to learn abstract material such as theories and their meanings and tend to be more innovative than sensing learners. Visual (Vis) learners remember best what they have seen whereas verbal (Ver) learners get more out of words, regardless whether they are spoken or written. Sequential (Seq) learners learn in linear steps and prefer to follow linear stepwise paths whereas global $(G)$ learners learn in large leaps and are characterized as holistic.

In order to detect both the preference itself and the degree of preference of learners for each dimension, the Index of Learning Styles (ILS) questionnaire has been developed by Felder and Soloman (1997). The ILS is a 44-item questionnaire which aims at identifying the learning styles according to
FSLSM and is also the only validated tool at the present time.

In this paper, we analyse data gathered from the ILS questionnaire by using data-driven approaches (Cherkassky \& Mulier, 1998). Data driven approaches can provide some useful methods aiming at discovering unexpected latent knowledge and relationships inside educational data, and graphical exploratory analysis (Wilkinson, I999) is well known for the purpose, and has been experimented on ILS data leading to unexpected results with respect to some correlations between styles (Graf, Viola, Kinshuk \& Leo, 2006).

The aim of this paper is to investigate impacts and relationships between learning style dimensions or, more concretely, between all eight styles since each dimension consists of two poles. Furthermore, we aim at investigating whether each style is influenced only by the ILS questions devoted to detect it, as it is expected by Felder and Soloman.

In the next section, we give an introduction in the materials and methods we used. Subsequently, the results achieved from these methods are presented in section 3 and are discussed in section 4 . Furthermore, the comparison with results on statistical properties of ILS is provided and discussed, pointing out the importance of consistency and coherence of mathematical and statistical assumptions with respect to the characteristics of data. Section 5 concludes the paper.

\section{MATERIALS AND METHODS}

The ILS questionnaire proposes a list of questions used to identify the learning style of each learner. The resulting index of preference for each dimension is expressed by an odd integer ranging [-II, +II], since II questions are posed for each of the four dimensions $D I M=\{A / R, S E N / I, V I S / V E R, S E 2 / G\}$, with steps $+/-2$. For each question TYPE there are two possible values: $+I$ if the answer expresses the preference for the first style, -I if the answer expresses the preference for the second style. As an example, when answering a question with an active preference, the learner's score is incremented by $+\mathrm{I}$ while for reflective preference the score is decreased by I (i.e. - I is added).

The degree of preference for each dimension is just the algebraic sum of all values of the answers to the eleven questions

$$
i_{D I M}=\sum_{i=1}^{11} q_{i}^{D I M}
$$


The vector of indexes $I=\left\{i_{A / R}, i_{S E N / I}, i_{V I S / V E R}, i_{S E 2 / G}\right\}$ is a four feature vector containing the index of learning styles for each FS dimension. $2_{D I M}=$ $\left\{q_{I}^{D I M}, q_{I I}^{D I M}\right\}$ is the set of questions belonging to each dimension. Answers to questions are expressed on a binary scale; the Index is expressed on an ordinal scale in which only the dominant preference (i.e. the difference between positive and negative values) is explicitly given.

For the analysis a dataset containing the ILS answers of 207 individuals collected at Vienna University of Technology (85 individuals) and at Massey University in New Zealand (I22 individuals) was used. The ILS matrix $M$ is obtained from the dataset. Let $M$ be the $207 \times 44$ matrix containing one row per learner and one column per ILS answers. The matrix $M$ contains then positive and negative values expressed according to a binary scale.

From a statistical viewpoint, binary data such as the ones of ILS presents some peculiarities in behaviour that cannot be addressed using classical statistics. In fact, the geometrical configuration space of two binary variables, $x_{1}$ and $x_{2}$ in $\mathfrak{R}^{2}$, is the set of the four extreme points of the unit square because they are binary and as such cannot take on values within the interval. Figure I shows geometrically this behaviour.

In this setting, the concept of correlation between variables, as defined by Pearson, has to be redefined, and the redefinition leads to the concept of association between variables (Yule, I912; Pearson, I90I) that indicates the proportion of individuals that possess one character belonging to the first variable and one character of the second one with respect to the proportion of individuals that exibit the same

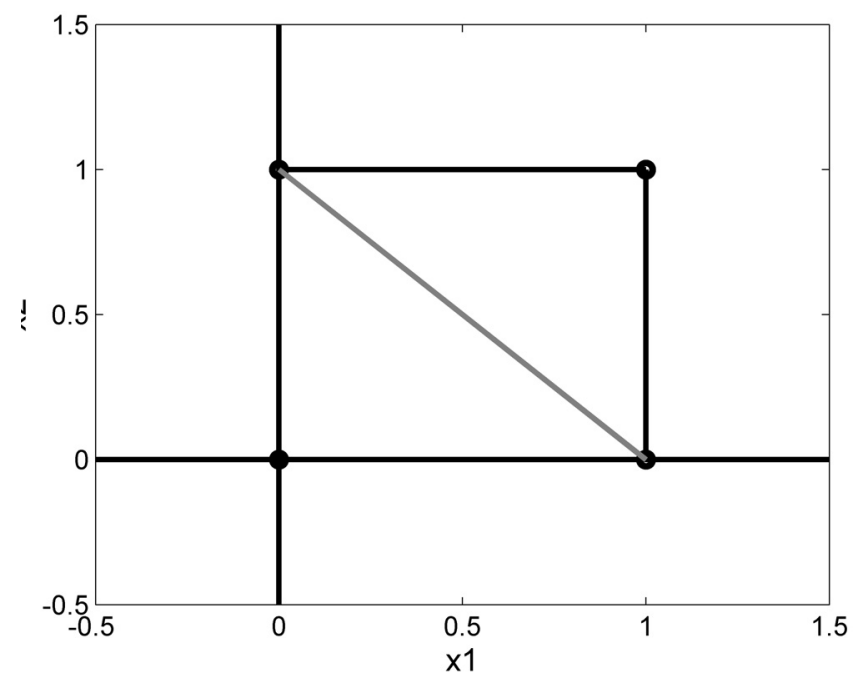

Figure 1 The binary data geometry in the two variables case (the square) and the extreme points of the left to right diagonal (the gray line) first character of the first variable, but the other of the second.

Furthermore, some classical variance-based statistics are no more reliable, since the underlying statistical assumptions do not hold; inside these, the correlation coefficients as defined by Pearson for numeral data are no more a reliable measure of association due to the geometry of the binary scale (Figure I). Moreover, consistency problems could arise in such an analysis: in fact, they could be due to the arbitrary way in which such kind of data are codified that underlines the absence of any metric in the sample space (Stevens, r946; Siegel \& Castellan, i988).

In order to make data consistent with the application of both classical correlation analysis, such as Pearson's coefficients and $p$ values, and with multivariate analysis, data can be transformed into frequencies, i.e. on absolute scale. When a binary variable represents two separate classes, such as the ILS questions, it is possible to derive from each variable $x_{i}$ two new variables $x_{i}^{(1)}$ and $x_{i}^{(2)}$, one for each binary class, that represent the frequency of occurrence of each class, with admissible values only in the set $\{\mathrm{O}, \mathrm{I}\}$. In this specific case the constraints $x_{i}^{(1)}+x_{i}^{(2)}=$ 1 holds, and the geometrical configuration of the two new variables $x_{i}^{(\mathrm{I})}$ and $x_{i}^{(2)}$ in $\mathfrak{R}^{2}$ is the set of the extreme points of the left to right diagonal of the unit square (Aitchison, I986), as shown in Figure I.

Referring to ILS, for every question $q_{I}, \mathrm{Q}=44,2$ numerical variables, namely the two answers to each question,

$$
\begin{aligned}
& a_{i}^{(1)}=1 \text { if } q_{I}=1,0 \text { otherwise } \\
& a_{i}^{(2)}=1 \text { if } q_{I}=-1,0 \text { otherwise }
\end{aligned}
$$

were obtained. Let $A$ be the $207 \times 88$ matrix containing in rows individuals and in columns the $a_{i}$, $i=\mathrm{I}, \ldots, 88$. Such a matrix, well known in multivariate statistics as complete disjunctive form of a matrix, represents the same information as the original matrix.

Learners showing a preference for each of the eight styles, irrespective with the strength of preference, were selected and grouped (Table I). More formally, all the students showing $i_{D I M}>0$ or $i_{D I M}<$ 0 , for each $D I M$ respectively were selected and grouped according to their preferences. Then the frequencies of answers to each of all 88 answers were counted and divided by the cardinality of each group of students.

Let $S$ be the matrix having in rows the frequencies of answers for each of the 88 answers and in columns the eight possible Felder-Silverman learning styles, i.e. the relative frequency of occurrence of a certain 
Table 1 Absolute and relative frequencies of occurrence of each style, irrespective for the degree of preference

\begin{tabular}{|c|c|c|c|c|c|c|c|c|}
\hline & A & R & Sen & I & Vis & Ver & Seq & G \\
\hline Fr & 117 & 90 & 120 & 87 & 181 & 26 & 91 & 116 \\
\hline$\%$ & 57 & 43 & 58 & 42 & 87 & 13 & 44 & 56 \\
\hline
\end{tabular}

answer inside the set of learners classified as belonging to a certain style. Then $S$ was decomposed according to Multiple Correspondence Analysis (MCA) (Greenacre, 1984; Lebart, Morineau \& Warwick, 1984) algorithm, and the first two non trivial axes, i.e. the second and the third, were selected for the low dimensional representation.

MCA is a well known multivariate technique for data dimensionality reduction and graphical exploration, especially for categorical data. MCA works performing the optimal projection of a matrix in rows and columns space simultaneously on few dimensions (usually two), looking at independence of each value according to chi square metric. In this study, the algorithm proposed by Greenacre (Greenacre, 1984) has been chosen. It consists of a Singular Value Decomposition (SVD) of the matrix $S$, weighted by positive definite diagonal matrices containing the inverse of the square roots of marginal frequencies; it is the generalization the theorem of the optimal k-rank approximation of a matrix given by the SVD to matrices weighted by diagonal positive definite matrices. Then the first 2 non trivial axes, that is the axes 2 and 3 , have been selected.

Such an analysis aims at investigating, coherently with statistical assumptions, the intersections of clusters of ILS questions, the occurrences between styles, and focuses not only on the number of shared scores, but rather on which items are shared. For cross validation procedure Pearson's correlation coefficients and related $p$ values of the matrix of relative frequencies per style were analysed.

\section{RESULTS}

In this section we describe results of MCA analysis and correlation analysis. Subsequently, the analysis of the clusters of answers nearest to each style are shown and finally we present the characterization of learning styles.

\subsection{Multiple Correspondence Analysis outcomes}

The results of MCA show that the matrix has, except for the first trivial singular value that is equal to I, two singular values of order of magnitude $\mathrm{IO}^{-\mathrm{I}}$, and two singular values of order of magnitude $\mathrm{IO}^{-2}$. They are all ordered in decreasing order by construction. The matrix has rank 5. In this study, only the first two non-trivial axes, that is the second and the third, corresponding to the first two non trivial singular values are considered.

Looking at the high represented answers on each axis of the model, the latent dimension underlying the first non trivial axis clearly refers to the visual or verbal preference: the positive semiaxis encodes the verbal preference, while the negative one encodes the visual preference. Nevertheless, other contributions in the negative semiaxis refer to the preference for a reversed social behaviour and for the need for having a whole vision of a subject; other contributions in the positive semiaxis refer to the preference for a regular learning process and to the attention for details.

The latent dimension underlying the second non trivial axis refers to the preference for :

a. what students prefer to learn: concrete facts or abstract theories and concepts;

b. the way in which students prefer to learn: bottom-up, inferential, regular, and careful with details or unregular, intuitive, top-down, and not careful with details.

The negative semiaxis encodes the preference for theories and unregular learning paths; the positive semiaxis encodes the preference for concrete material and regular learning paths.

According to these dimensions both the points representing styles and the points representing answers are arranged. Figure 2 shows the eight points representing the styles arranged in the plane given by the second and the third MCA axes. It can

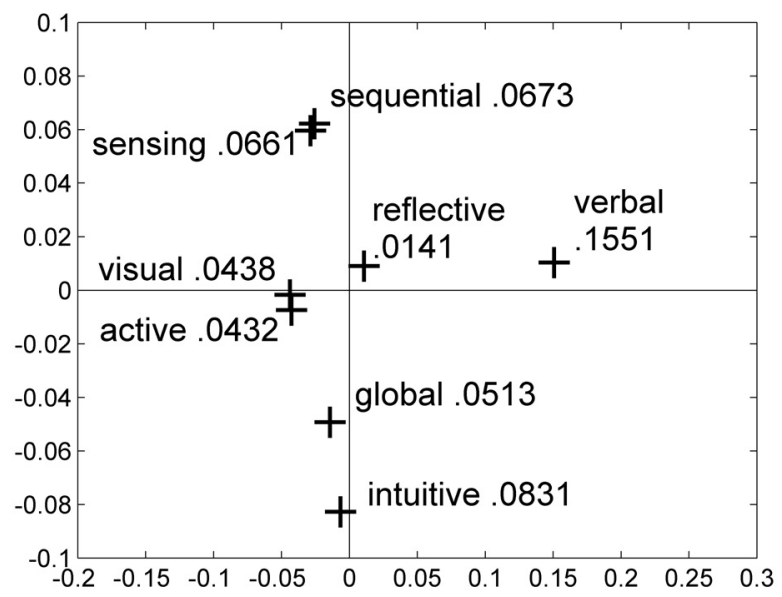

Figure 2 The eight styles on the MCA plane. The number near each label is the Euclidean distance of the point from zero 
be seen that:

a. some styles, belonging to different ILS dimensions, namely active and visual as well as sequential and sensing, are highly correlated;

b. the only styles that lie on the same straight line passing through zero in opposite directions in the MCA graphics are the visual and verbal styles, while the remaining others do not;

c. the remaining styles appear to be relatively independent to each others, even if belonging to the same ILS dimension.

\subsection{Correlation analysis}

Pearson's correlation coefficients, given in table 2, show that many dependencies between styles, in some cases also between styles belonging to the same ILS dimension (active/reflective .53 and sensing/intuitive .43) are found. $P$ values represent the probability of obtaining the same correlation coefficients in the case of no correlation (null hypothesis). The smaller the $p$ values, the greater the significance. According to the threshold .05, the correlation coefficients show to be significant in all cases except the ones belonging to visual dimension. These results could be motivated, in the setting of multivariate analysis, both by the contribution given to correlation by variables assessing different dimensions DIM and by the contribution given by variables assessing the dimension in analysis in the case of weak preference for a style, i.e. when $i_{D I M}=$ $+/$-I or $i_{D I M}=+/-3$. This also leads to hypothesize that some ILS dimensions assess two relatively independent latent variables rather than one variable having two opposite expressions.

\subsection{Analysis of the clusters of answers nearest to each style}

Table 3 shows the variables nearest to each style according to Euclidean distance in MCA plane. As can be seen from table 3, some intersections within the styles exist. In the following discussion, we show for each style how it is influenced by other styles. Therefore, we look at the first in questions, since for each style II questions exist that are developed to indicate a preference for the respective style. Additionally, discussion is provided over the first 25 questions to give a broader view whereby small influences based on one or two questions are not explicitly mentioned.

According to Figure 2 and Table 3, the active learning style is strongly influenced by the visual style. For the active style, the first nearest II questions are exactly the same than for the visual style and only two of them are developed for indicating an active preference. The other 9 questions are indicating a visual style. Considering the first 25 questions, all II questions indicating a visual preference are included but only 7 questions that indicate an active preference are incorporated. Also, some questions from other styles are included in the first 25, which is obvious since only II questions exist for an active style. These other questions are for sensing, intuitive, sequential, and global style and their influence is quite small. However, interesting is that no questions for a verbal style is included. This again shows that a relationship between an active and visual style exists. Regarding the similarity of the questions for the active and visual style, it seems that learners with an active style answer questions quite similarly to learners with a visual style. From a cognitive point of view, the relation between active and visual style can be explained from similar characteristics where, for example, active learners are likely to prefer to learn from charts and diagrams rather from verbal text.

The reflective style is quite different from the active style. Several other styles influence the reflective style. Looking at the first II questions, 5 questions indicate a reflective style, 4 questions indicate a sequential style, I question a sensing, and I a verbal style. Looking at the first 25 , we can see that 9

Table 2 Correlation coefficients of each style (upper triangular elements) and p values (lower triangular elements, in italic) of the matrix $\mathrm{S}$ in column space. In bold high (>.9) values

\begin{tabular}{|c|c|c|c|c|c|c|c|c|}
\hline Co & $\mathrm{A}$ & $\mathrm{R}$ & Sen & $\mathrm{I}$ & Vis & Ver & Seq & $\mathrm{G}$ \\
\hline $\mathrm{A}$ & $\mathrm{l}$ & .53 & .82 & .72 & $\mathbf{. 9 2}$ & .03 & .77 & .84 \\
\hline $\mathrm{R}$ & 0 & 1 & .76 & .62 & .80 & .25 & .73 & .73 \\
\hline Sen & 0 & 0 & 1 & .43 & $\mathbf{. 9 0}$ & .15 & $\mathbf{. 9 1}$ & .71 \\
\hline $\mathrm{I}$ & 0 & 0 & 0 & $\mathrm{l}$ & .77 & .06 & .47 & .86 \\
\hline Vis & 0 & 0 & 0 & 0 & 1 & .02 & .86 & .89 \\
\hline Ver & .77 & .01 & .15 & .54 & .87 & $\mathrm{l}$ & .10 & .13 \\
\hline Seq & 0 & 0 & 0 & 0 & 0 & .32 & 1 & .56 \\
\hline $\mathrm{G}$ & 0 & 0 & 0 & 0 & 0 & .20 & 0 & 1 \\
\hline
\end{tabular}


Table 3 The nearest variables to each style vector according to Euclidean distance (in italic) in the MCA plane

\begin{tabular}{|c|c|c|c|c|c|c|c|}
\hline$\overline{\mathbf{A}}$ & $\overline{\mathbf{R}}$ & Sen & $\bar{I}$ & Vis & Ver & Seq & $\bar{G}$ \\
\hline $\begin{array}{c}31 \mathrm{a} \\
0.005\end{array}$ & $\begin{array}{c}28 \mathrm{a} \\
0.004\end{array}$ & $\begin{array}{c}36 \mathrm{a} \\
0.029\end{array}$ & $\begin{array}{c}38 \mathrm{a} \\
0.049\end{array}$ & $\begin{array}{c}31 \mathrm{a} \\
0.007\end{array}$ & $\begin{array}{c}31 \mathrm{~b} \\
0.090\end{array}$ & $\begin{array}{c}36 \mathrm{a} \\
0.031\end{array}$ & $\begin{array}{c}38 \mathbf{b} \\
0.022\end{array}$ \\
\hline $\begin{array}{c}7 \mathrm{a} \\
0.012\end{array}$ & $\begin{array}{c}37 \mathrm{~b} \\
0.005\end{array}$ & $\begin{array}{c}14 \mathrm{a} \\
0.039\end{array}$ & $\begin{array}{c}6 \mathrm{~b} \\
0.055\end{array}$ & $\begin{array}{c}7 \mathrm{a} \\
0.013\end{array}$ & $\begin{array}{c}11 \mathrm{~b} \\
0.105\end{array}$ & $\begin{array}{c}14 \mathrm{a} \\
0.040\end{array}$ & $\begin{array}{c}44 \mathrm{~b} \\
0.027\end{array}$ \\
\hline $\begin{array}{c}11 \mathrm{a} \\
0.012\end{array}$ & $\begin{array}{c}25 \mathrm{~b} \\
0.006\end{array}$ & $\begin{array}{c}10 \mathrm{a} \\
0.042\end{array}$ & $\begin{array}{c}18 \mathrm{~b} \\
0.056\end{array}$ & $\begin{array}{c}11 \mathrm{a} \\
0.014\end{array}$ & $\begin{array}{c}7 \mathrm{~b} \\
0.105\end{array}$ & $\begin{array}{c}10 \mathrm{a} \\
0.042\end{array}$ & $\begin{array}{c}22 \mathrm{~b} \\
0.028\end{array}$ \\
\hline $\begin{array}{c}15 \mathrm{a} \\
0.016\end{array}$ & $\begin{array}{c}40 \mathrm{a} \\
0.006\end{array}$ & $\begin{array}{c}38 \mathrm{a} \\
0.042\end{array}$ & $\begin{array}{c}44 \mathrm{~b} \\
0.059\end{array}$ & $\begin{array}{c}19 \mathrm{a} \\
0.019\end{array}$ & $\begin{array}{c}19 \mathrm{~b} \\
0.108\end{array}$ & $\begin{array}{c}38 \mathrm{a} \\
0.043\end{array}$ & $\begin{array}{c}18 \mathbf{b} \\
0.029 \\
\end{array}$ \\
\hline $\begin{array}{c}19 \mathrm{a} \\
0.019\end{array}$ & $\begin{array}{c}30 \mathrm{a} \\
0.007\end{array}$ & $\begin{array}{c}26 \mathrm{a} \\
0.044\end{array}$ & $\begin{array}{c}22 \mathrm{~b} \\
0.059\end{array}$ & $\begin{array}{c}15 \mathrm{a} \\
0.019\end{array}$ & $\begin{array}{c}3 \mathrm{~b} \\
0.115\end{array}$ & $\begin{array}{c}26 \mathrm{a} \\
0.045\end{array}$ & $\begin{array}{c}30 \mathrm{~b} \\
0.030\end{array}$ \\
\hline $\begin{array}{c}41 \mathrm{a} \\
0.023\end{array}$ & $\begin{array}{c}33 \mathrm{~b} \\
0.007\end{array}$ & $\begin{array}{c}6 \mathrm{a} \\
0.045\end{array}$ & $\begin{array}{c}36 \mathrm{~b} \\
0.061\end{array}$ & $\begin{array}{c}1 \mathrm{a} \\
0.024\end{array}$ & $\begin{array}{l}27 \mathrm{~b} \\
0.116\end{array}$ & $\begin{array}{c}6 \mathrm{a} \\
0.046\end{array}$ & $\begin{array}{c}6 \mathrm{~b} \\
0.031\end{array}$ \\
\hline $\begin{array}{c}27 \mathrm{a} \\
0.024\end{array}$ & $\begin{array}{c}4 \mathrm{lb} \\
0.009\end{array}$ & $\begin{array}{c}18 \mathrm{a} \\
0.045\end{array}$ & $\begin{array}{c}2 \mathrm{~b} \\
0.062\end{array}$ & $\begin{array}{c}39 \mathrm{a} \\
0.024\end{array}$ & $\begin{array}{c}23 \mathrm{~b} \\
0.119\end{array}$ & $\begin{array}{c}18 \mathrm{a} \\
0.046\end{array}$ & $\begin{array}{c}20 \mathrm{~b} \\
0.032\end{array}$ \\
\hline $\begin{array}{c}3 \mathrm{a} \\
0.024\end{array}$ & $\begin{array}{c}17 \mathrm{~b} \\
0.010\end{array}$ & $\begin{array}{c}42 \mathrm{a} \\
0.048\end{array}$ & $\begin{array}{c}10 \mathrm{~b} \\
0.063\end{array}$ & $\begin{array}{c}27 \mathrm{a} \\
0.024\end{array}$ & $\begin{array}{c}43 \mathrm{~b} \\
0.121\end{array}$ & $\begin{array}{c}22 a \\
0.049\end{array}$ & $\begin{array}{c}2 \mathrm{~b} \\
0.032\end{array}$ \\
\hline $\begin{array}{c}39 \mathrm{a} \\
0.024\end{array}$ & $\begin{array}{c}4 \mathrm{a} \\
0.011\end{array}$ & $\begin{array}{c}22 \mathrm{a} \\
0.048\end{array}$ & $\begin{array}{c}20 \mathrm{~b} \\
0.063\end{array}$ & $\begin{array}{c}3 \mathrm{a} \\
0.025\end{array}$ & $\begin{array}{c}1 \mathrm{~b} \\
0.123\end{array}$ & $\begin{array}{c}42 \mathrm{a} \\
0.049\end{array}$ & $\begin{array}{c}10 \mathrm{~b} \\
0.034\end{array}$ \\
\hline $\begin{array}{c}23 \mathrm{a} \\
0.025\end{array}$ & $\begin{array}{c}15 \mathrm{~b} \\
0.011\end{array}$ & $\begin{array}{c}8 \mathrm{a} \\
0.049\end{array}$ & $\begin{array}{c}30 \mathrm{~b} \\
0.064\end{array}$ & $\begin{array}{c}23 \mathrm{a} \\
0.026\end{array}$ & $\begin{array}{c}39 \mathrm{~b} \\
0.125\end{array}$ & $\begin{array}{c}8 \mathrm{a} \\
0.051\end{array}$ & $\begin{array}{c}14 \mathbf{b} \\
0.038\end{array}$ \\
\hline $\begin{array}{c}1 \mathrm{a} \\
0.03\end{array}$ & $\begin{array}{l}20 \mathrm{a} \\
0.01\end{array}$ & $\begin{array}{l}44 \mathrm{a} \\
0.05\end{array}$ & $\begin{array}{l}14 \mathrm{~b} \\
0.06\end{array}$ & $\begin{array}{c}1 \mathrm{a} \\
0.03\end{array}$ & $\begin{array}{l}15 \mathrm{~b} \\
0.13\end{array}$ & $\begin{array}{l}44 a \\
0.05\end{array}$ & $\begin{array}{l}32 \mathrm{~b} \\
0.04\end{array}$ \\
\hline $\begin{array}{l}33 \mathrm{a} \\
0.03\end{array}$ & $\begin{array}{l}35 b \\
0.01\end{array}$ & $\begin{array}{c}2 \mathrm{a} \\
0.05\end{array}$ & $\begin{array}{l}32 \mathrm{~b} \\
0.07\end{array}$ & $\begin{array}{l}33 a \\
0.03\end{array}$ & $\begin{array}{l}41 \mathrm{~b} \\
0.13\end{array}$ & $\begin{array}{c}2 \mathrm{a} \\
0.05\end{array}$ & $\begin{array}{l}36 \mathrm{~b} \\
0.04\end{array}$ \\
\hline $\begin{array}{l}43 \mathrm{a} \\
0.03\end{array}$ & $\begin{array}{c}5 \mathrm{a} \\
0.01\end{array}$ & $\begin{array}{l}24 a \\
0.05\end{array}$ & $\begin{array}{l}42 \mathrm{~b} \\
0.07\end{array}$ & $\begin{array}{l}43 a \\
0.03\end{array}$ & $\begin{array}{l}35 \mathrm{~b} \\
0.13\end{array}$ & $\begin{array}{l}20 \mathrm{a} \\
0.05\end{array}$ & $\begin{array}{l}16 \mathrm{~b} \\
0.04\end{array}$ \\
\hline $\begin{array}{l}30 \mathrm{~b} \\
0.03\end{array}$ & $\begin{array}{l}13 \mathrm{a} \\
0.01\end{array}$ & $\begin{array}{l}20 \mathrm{a} \\
0.05\end{array}$ & $\begin{array}{l}26 \mathrm{~b} \\
0.07\end{array}$ & $\begin{array}{l}35 \mathrm{a} \\
0.03\end{array}$ & $\begin{array}{l}33 \mathrm{~b} \\
0.13\end{array}$ & $\begin{array}{l}24 a \\
0.05\end{array}$ & $\begin{array}{l}26 \mathrm{~b} \\
0.04\end{array}$ \\
\hline $\begin{array}{l}35 \mathrm{a} \\
0.03\end{array}$ & $\begin{array}{l}44 a \\
0.01\end{array}$ & $\begin{array}{l}32 \mathrm{a} \\
0.05\end{array}$ & $\begin{array}{l}12 \mathrm{~b} \\
0.07\end{array}$ & $\begin{array}{l}37 \mathrm{a} \\
0.03\end{array}$ & $\begin{array}{l}29 \mathrm{~b} \\
0.14\end{array}$ & $\begin{array}{c}4 \mathrm{a} \\
0.05\end{array}$ & $\begin{array}{c}4 \mathrm{~b} \\
0.04\end{array}$ \\
\hline $\begin{array}{l}37 \mathrm{a} \\
0.03\end{array}$ & $\begin{array}{c}2 \mathrm{a} \\
0.01\end{array}$ & $\begin{array}{c}4 \mathrm{a} \\
0.05\end{array}$ & $\begin{array}{l}16 \mathrm{~b} \\
0.07\end{array}$ & $\begin{array}{l}30 \mathrm{~b} \\
0.03\end{array}$ & $\begin{array}{l}30 \mathrm{a} \\
0.14\end{array}$ & $\begin{array}{l}32 \mathrm{a} \\
0.05\end{array}$ & $\begin{array}{l}15 \mathrm{a} \\
0.04\end{array}$ \\
\hline $\begin{array}{l}29 \mathrm{a} \\
0.04\end{array}$ & $\begin{array}{c}9 \mathrm{~b} \\
0.01\end{array}$ & $\begin{array}{l}34 a \\
0.05\end{array}$ & $\begin{array}{c}\mathrm{b} \\
0.07\end{array}$ & $\begin{array}{l}29 a \\
0.03\end{array}$ & $\begin{array}{l}37 \mathrm{~b} \\
0.14\end{array}$ & $\begin{array}{l}34 a \\
0.06\end{array}$ & $\begin{array}{c}8 \mathrm{~b} \\
0.04\end{array}$ \\
\hline $\begin{array}{l}34 \mathrm{a} \\
0.04\end{array}$ & $\begin{array}{l}21 \mathrm{~b} \\
0.01\end{array}$ & $\begin{array}{l}12 \mathrm{a} \\
0.05\end{array}$ & $\begin{array}{c}4 \mathrm{~b} \\
0.07\end{array}$ & $\begin{array}{l}34 a \\
0.04\end{array}$ & $\begin{array}{l}36 \mathrm{~b} \\
0.14\end{array}$ & $\begin{array}{l}12 \mathrm{a} \\
0.06\end{array}$ & $\begin{array}{l}42 \mathrm{~b} \\
0.04\end{array}$ \\
\hline $\begin{array}{l}25 \mathrm{a} \\
0.04\end{array}$ & $\begin{array}{l}16 \mathrm{a} \\
0.01\end{array}$ & $\begin{array}{l}29 \mathrm{a} \\
0.06\end{array}$ & $\begin{array}{l}24 \mathrm{~b} \\
0.07\end{array}$ & $\begin{array}{l}24 a \\
0.04\end{array}$ & $\begin{array}{l}42 \mathrm{~b} \\
0.14\end{array}$ & $\begin{array}{l}16 \mathrm{a} \\
0.06\end{array}$ & $\begin{array}{l}12 \mathrm{~b} \\
0.04\end{array}$ \\
\hline $\begin{array}{l}24 \mathrm{a} \\
0.04\end{array}$ & $\begin{array}{l}32 \mathrm{a} \\
0.01\end{array}$ & $\begin{array}{l}16 \mathrm{a} \\
0.06\end{array}$ & $\begin{array}{l}29 \mathrm{~b} \\
0.08\end{array}$ & $\begin{array}{l}42 a \\
0.04\end{array}$ & $\begin{array}{l}28 \mathrm{a} \\
0.14\end{array}$ & $\begin{array}{l}29 a \\
0.06\end{array}$ & $\begin{array}{l}25 a \\
0.04\end{array}$ \\
\hline $\begin{array}{l}28 \mathrm{~b} \\
0.04\end{array}$ & $\begin{array}{l}21 \mathrm{a} \\
0.02\end{array}$ & $\begin{array}{l}39 \mathrm{a} \\
0.06\end{array}$ & $\begin{array}{l}28 \mathrm{~b} \\
0.08\end{array}$ & $\begin{array}{l}25 \mathrm{a} \\
0.04\end{array}$ & $\begin{array}{l}24 \mathrm{~b} \\
0.14\end{array}$ & $\begin{array}{l}28 \mathrm{a} \\
0.06\end{array}$ & $\begin{array}{l}28 \mathrm{~b} \\
0.04\end{array}$ \\
\hline $\begin{array}{l}40 \mathrm{~b} \\
0.04\end{array}$ & $\begin{array}{l}22 \mathrm{a} \\
0.02\end{array}$ & $\begin{array}{c}1 \mathrm{a} \\
0.06\end{array}$ & $\begin{array}{l}25 \mathrm{a} \\
0.08\end{array}$ & $\begin{array}{l}12 a \\
0.04\end{array}$ & $\begin{array}{l}12 \mathrm{~b} \\
0.14\end{array}$ & $\begin{array}{l}30 \mathrm{a} \\
0.06\end{array}$ & $\begin{array}{l}40 \mathrm{~b} \\
0.04\end{array}$ \\
\hline $\begin{array}{l}42 \mathrm{a} \\
0.04\end{array}$ & $\begin{array}{l}13 \mathrm{~b} \\
0.02\end{array}$ & $\begin{array}{l}28 a \\
0.06\end{array}$ & $\begin{array}{l}15 \mathrm{a} \\
0.08\end{array}$ & $\begin{array}{l}28 \mathrm{~b} \\
0.04\end{array}$ & $\begin{array}{l}34 \mathrm{~b} \\
0.14\end{array}$ & $\begin{array}{l}39 a \\
0.06\end{array}$ & $\begin{array}{l}33 \mathrm{a} \\
0.04\end{array}$ \\
\hline $\begin{array}{l}17 \mathrm{a} \\
0.04\end{array}$ & $\begin{array}{c}5 \mathrm{~b} \\
0.02\end{array}$ & $\begin{array}{c}9 \mathrm{~b} \\
0.06\end{array}$ & $\begin{array}{l}40 \mathrm{~b} \\
0.08\end{array}$ & $\begin{array}{l}40 \mathrm{~b} \\
0.04\end{array}$ & $\begin{array}{l}14 \mathrm{~b} \\
0.14\end{array}$ & $\begin{array}{c}9 \mathrm{~b} \\
0.06\end{array}$ & $\begin{array}{l}37 \mathrm{a} \\
0.05\end{array}$ \\
\hline $\begin{array}{l}12 \mathrm{a} \\
0.04\end{array}$ & $\begin{array}{l}34 b \\
0.02\end{array}$ & $\begin{array}{l}35 \mathrm{a} \\
0.06\end{array}$ & $\begin{array}{l}34 \mathrm{~b} \\
0.08\end{array}$ & $\begin{array}{c}8 \mathrm{a} \\
0.04\end{array}$ & $\begin{array}{l}25 b \\
0.15\end{array}$ & $\begin{array}{c}1 \mathrm{a} \\
0.06\end{array}$ & $\begin{array}{l}11 \mathrm{a} \\
0.05\end{array}$ \\
\hline
\end{tabular}

questions indicate a reflective style, 7 indicates a sequential style, 3 a sensing style, 2 a verbal style and I an intuitive style. Also interesting is that 3 questions indicate an active preference which is conflictive to the expectations, since the active and reflective style are, according to ILS, on the same dimension but on the opposite poles. This adds evidence and supports the hypothesis that ILS dimensions should be considered not unidimensional. The only style that does not occur is the visual style, which again might show the relationship of the visual style to the active style rather than to the reflective one. From the results in Table 3, we can conclude that the reflective style is mostly influenced by questions regarding a reflective style (as it should be) as well as by questions about a sequential style.

The sensing learning style is strongly dependent from questions for a sensing style. Within the first II questions, 8 questions are about a sensing style and the remaining 3 are about a sequential style. Considering the first 25 questions, Io questions for the sensing style and also ro questions about the sequential style are included. For this dimension we can say that questions about a sensing preference play the most important role and also some influences from the sequential style exist. These 
influences can be explained by the relationship between the sensing and the sequential style which is already discovered in literature (e.g. Felder \& Spurlin, 2005) and also found by our results (e.g. see Table 2). From a cognitive point of view the reason might be seen again in similar characteristics, for example both, sensing and sequential learners have a preference for details.

The intuitive style shows similar tendencies as the sensing style. Again, within the first II questions, 8 are regarding the intuitive style and 3 are based on the global style. Considering the first 25 questions, all II questions from the intuitive style and all II questions from the global style are included. These results show that the intuitive style is strongly influenced by questions about intuitive preferences and also that global preferences seem to be relevant. The influence of the global style might come from the relationship between sensing and sequential styles, since these are the other poles on the respective dimensions.

Also the visual style shows a strong dependency on questions developed for indicating the visual style. 9 out of the first in questions are about the visual style and the other two questions are on rank I3 and I4. These results show that the questions seem to fit very well and are highly significant. Looking at the first 25 questions, also the active style (5 questions) has some influence. This is in agreement with the discussion about the active style where we found a strong influence by questions about the visual style.

For the verbal style, Io out of the first II questions are about a preference for the verbal style and the other question is on rank 13. Again, this points out a very strong influence of the questions regarding the verbal style. Also here a small impact of the active/reflective dimension can be seen. 6 questions within the first 25 questions indicate a reflective style.

Regarding the sequential style, it is interesting to see that the first 20 questions are exactly in agreement with the sensing style. All questions achieve the same rank or have maximum one rank difference. That also means that 8 questions out of the first II are about the sensing style and only the remaining 3 indicate a sequential preference. Considering the first 25 questions, IO questions of the sequential style and all II questions of the sensing style are included. The reason for this strong influence of the sensing style might be seen in the correlation with the sequential style. From the $\operatorname{cog}$ nitive view, we know that some preferences, e.g. the preference for details, is characteristic for sensing and sequential learners. As a conclusion, we can say that learners with a sequential learning style seem to answer questions quite equally to learners with a sensing style (and vice versa).

The results of the global style are quite similar but do not show such a strong relationship. It can also be seen that these questions have high correlation with the questions from the intuitive dimension. Again, 8 out of the first II questions indicate an intuitive style and only 3 a global style. Looking at the first 25 questions, Io questions are about a global preference and io questions are about an intuitive preference. The strong influence of the intuitive style might be again based on the correlation of the sensing and sequential dimension. The intuitive style seems to have more influence than the global style, as it is also true for the sequential style with respect to the sensing style.

\subsection{Learning styles characterization}

From the results of tables 2 and 3 we can draw two kinds of conclusions concerning the characterization of learning styles. Firstly, we can focus on the influences between the styles. Concerning this matter, it can be seen that the detection of the sensing, intuitive, visual, and verbal style seems to work as expected, so that questions indicating the respective style have the greatest influence. For the active style questions about a visual preference has the strongest impact, for the sequential style questions about a sensing preference have the strongest impact, and for a global style questions about an intuitive style have the strongest impact. For the last mentioned styles, questions about the respective style have only second highest impact. For the reflective style, questions about a reflective style and also about a sequential style have both strong impact.

Secondly, we can look at groups of styles that are strongly related to each other. From the interpretation above, it can be seen that a strong relation between the active and visual style, the sensing and sequential style as well as the intuitive and global style exists. More concretely, the answers given by the active and visual groups show the sharing of a high percentange of similar answers. The shared answers refers to the preference for pictures, charts diagrams or multimedia above all (answers 3ia, 7a, IIa, I5a, 27a, 3a, 39a, 23a), but also with the better processing and retention of visual or perceptual and experiential information (19a, 43a, 35a, 34a, 1a, 25a), and the preference for collaborative work (4Ia, $30 \mathrm{Ob}$ ). Regarding the sensing and sequential styles, the shared answers refers to the preference for concrete material (I4a, IOa, 38a, 26a, I8a, 2a, 34a, 29a) and to 
the preference for a regular and bottom-up learning, as well as to the attention for details (36a, 22a, 42a, 8a, 44a, 20a, 24a, 4a, 32a, I2a, 16a). Regarding the intuitive and global styles, the shared answers refer to the preference for abstract material and theories (38b, 6b, I8b, 6b, Iob, I 4 b) and the preference for an unregular and top-down learning, as well as to the scarce attention for details $(44 \mathrm{~b}, 22 \mathrm{~b}, 3 \mathrm{Ob}, 2 \mathrm{Ob}, 44 \mathrm{~b}$, $36 \mathrm{~b}, 2 \mathrm{~b}, 2 \mathrm{Ob}, 32 \mathrm{~b}, 16 \mathrm{~b}, 42 \mathrm{~b}, 26 \mathrm{~b}, 4 \mathrm{~b}, \mathrm{I} 2 \mathrm{~b})$, although, looking at low ranked answers, a difference between intuitive and global can be noticed. Regarding the intersections between clusters of variables, it can be seen that they are coherent with the latent dimensions underlying the first and second axis of the model, according to Figure 2.

From statistical viewpoint, these results can be motivated looking at the behaviour that is variance and dependencies sensitive, of multivariate methods. In fact, visual is the most populated group (table I) and visual/active is the most high correlation, as well as high correlations, together with consistent variances, are achieved by sensing/sequential, and intuitive/global styles. The results seem also to indicate that some styles share a percentage of similar answers with other styles so high that some answers appear to be redundant.

\section{DISCUSSIONS}

In this section we compare our results to the results obtained from other studies and subsequently we discuss relapses of our results for e-learning.

\subsection{Comparison with the literature}

In the literature, some contributions (Zywno, 2003; Litzinger, Lee \& Wise, 2005; Felder \& Spurlin, 2005) provide an analysis of ILS questionnaire for
Table 4 Results for Cronbach's alpha coefficients. *All the results marked with * are drawn from (Felder \& Spurlin, $2005) ; * *$ (Zywno, 2003) considers only 4 poles scores, that is active, sensing, visual, sequential

\begin{tabular}{c|c|c|c|c|c}
\hline Alpha & A/R & Sen/I & Vis/Ver & Seq/G & Size \\
\hline (Zywno, 2003) $^{* *}$ & .595 & .697 & .633 & .51 & $>500$ \\
\hline Livesay et al. $^{*}$ & .56 & .72 & .76 & .65 & 242 \\
\hline Spurlin ${ }^{*}$ & .62 & .76 & .69 & .55 & 584 \\
\hline Van Zwanenberg ${ }^{*}$ & .51 & .65 & .56 & .41 & 284 \\
\hline Litzinger et al. 2005 & .60 & .77 & .74 & .56 & 572 \\
\hline S 88 cols & .528 & .631 & .63 & .427 & 207 \\
\hline
\end{tabular}

what concerns internal consistency reliability and validity. Internal consistency is the extent to which a set of items can be considered as measuring a single latent variable, and is calculated by using Cronbach's alpha coefficients (Cronbach, 195I). Validity is the extend to which a tool actually measures the latent variable that it is devoted at measuring and is calculated by using Factor Analysis and Pearson's correlation coefficients.

Results on Cronbach's alpha (Table 4) achieved in our study are generally in agreement with the ones provided by literature; the alpha value for sequential/global, that is less than most other, is nevertheless shared with the study by Van Zwanenberg, whose results are drawn from a dataset more similar in size to the one used here.

However, it seems in general that alpha coefficients are not high, even if greater than the threshold .5, and this led to conclude for the co-existence of different latent dimensions underlying each ILS dimension that could not be peculiar to one dimension only. This hypothesis seems also to be confirmed when characterizing preferences of ILS dimensions are searched (Graf, Viola, Kinshuk \& Leo, 2006).

Similar comparisons were performed for validity and inter-scale orthogonality, although these are of

Table 5 Factor loadings of the first 3 PCA factors (singular values greater than 20) for the ILS M matrix

\begin{tabular}{|c|c|c|c|c|c|}
\hline & & $\mathrm{A} / \mathrm{R}$ & $\mathrm{Sen} / \mathrm{I}$ & Vis/Ver & $\mathrm{Seq} / \mathrm{G}$ \\
\hline \multicolumn{6}{|c|}{ Factor I } \\
\hline \multirow{2}{*}{$>|2|$} & + & & & & 28 \\
\hline & z & 29,1 & 6 & $11,23,7,19,3,27,31,43$ & \\
\hline \multirow{2}{*}{$>|-1|$} & \pm & 17 & 26 & & 4 \\
\hline & Z & & $2,38,18$ & 35,39 & $32,16,12$ \\
\hline \multicolumn{6}{|c|}{ Factor 2} \\
\hline$>|3|$ & + & & 38 & & \\
\hline$>|2|$ & + & & $22,10,18,6,2,30,14$ & & 36,44 \\
\hline \multirow{2}{*}{$>|.1|$} & + & & $34,42,26$ & & $20,4,8,28$ \\
\hline & - & $25,33,9,41,37$ & & $11,31,15,7$ & \\
\hline \multicolumn{6}{|c|}{ Factor 3} \\
\hline$>|4|$ & - & 37 & & & \\
\hline$>|2|$ & - & $21,5,13,1,9,41$ & 6 & & \\
\hline$>|-1|$ & + & & $30,22,2$ & 3,23 & \\
\hline & - & 25,29, & $38,10,18$, & 39 & \\
\hline
\end{tabular}


uncertain meaning because of the different scales of data and procedures used. For what concerns Pearson's correlation coefficients, that are shown in table 2, they are quite different from, and generally higher than, the ones given in literature. However, these coefficients are said in all works except in (Zywno, 2003) to be drawn from the analysis of scale scores, that are not expressed in absolute scale. For this reason, it can be hypothesized that the different results achieved here can be due to the sensitivity of Pearson's coefficients to the variance and the measurement scale of data. It is in fact known that for reliability of Pearson's coefficients, variables have to be expressed at least on interval scale (Hill \& Lewicki, 2006).

In particular, in (Felder and Spurlin, 2005) and (Zywno, 2003) correlations between sensing/intuitive and sequential/global dimensions (between .3 and .5) are attested. Other correlations of uncertain strength are pointed out between active/reflective and visual/verbal (between .03 and .I8), between active/reflective and sequential/global (between .or and .I8) and between visual/verbal and sensing/intuitive dimensions (between .03 and .II). The highest values are achieved in (Zywno, 2003), where an absolute scale is used. Then the correlation of uncertain strength and meaning could be reasonably sustained from the strong correlation of only one pole of the ILS dimension.

For what concerns Factor Analysis, we will limit the comparison to orthogonal factors, since for Oblique Factors the assumption of orthogonality does not hold. Factor loadings of ILS items are provided by (Felder \& Spurlin, 2005), (Litzinger, Lee \& Wise, 2005), and (Zywno, 2003) even if different procedures are used in each of these studies.

In order to guarantee a minimal comparability with other results, we performed Principal Component Analysis (PCA) (Jolliffe, 1986) on ILS 44 items matrix $M$ using Singular Value Decomposition (SVD). The matrix is full rank and all singular values have values greater than $\mathrm{I}$. If the eigenvalues of the covariance matrix are considered, I4 eigenvalues and related factors satisfy the Kaiser criterion (eigenvalues greater than I) with a cumulative percentage of variance of about $57 \%$. This is in agreement with (Zywno, 2003), (Litzinger, Lee \& Wise, 2005) and (Felder \& Spurlin, 2005).

However, if the loading of items on Right Singular Vectors are considered (Table 5) it can be pointed out that the results are quite different from the ones given in literature. While in fact in all works the number of questions highly represented by each factor, when provided, lead reasonably to conclude for the presence of some multivariate dependencies between styles, nevertheless the high loading clusters of items on each factors are different. In both (Litzinger, Lee \& Wise, 2005) and (Zywno, 2003) absolute values of coefficients are generally higher and clusters of items belonging to sensing/intuitive dimension load high on the first factor, while on other factors clusters and high loading dimensions are different from each other. Moreover, little information is given about the relative directions of coefficients with respect to zero.

While the high loading of clusters of visual/verbal dimensions in Table 5 can be motivated since this dimension is the one achieving the highest variance (Table I), little information is given in literature for explaining this uncertain behaviour. Moreover, although clusters of questions belonging to the same style are represented on each factor in all studies considered here, both the absolute values of coefficients and the number of questions highly loaded on each factor lead to conclude for the presence of dependencies in ILS dimensions.

For all these reasons, it seems then reasonable to hypothesize that the basic assumption of ILS, that is that every pairwise coupled styles belong to the same latent dimension in opposite ways, has to be investigated in depth using appropriate and coherent statistical procedures. From a statistical viewpoint, in fact, great differences arise when the multivariate dependencies between clusters of ILS questions are searched according to a data-driven approach, with respect to when only the scores are considered. According to the Theory of Measurement (Stevens, 1946; Siegel \& Castellan, I988) the quantities $i_{D I M}$ are measured on an ordinal scale. While the frequencies of occurrences of each question are expressed on an absolute scale and thus are equal to or greater than zero, the index $i_{D I M}$ admits also negative values. Furthermore, being the only admissible transformation with respect to absolute scale the identity, the index $i_{D I M}$ cannot be considered an admissible transformation of the variables representing the frequencies of the answers.

Eventually, a comparison of these outcomes with the results evidences the great difference that different data representation could bring to the analysis outcomes and the sensitivity of statistical methods for data representation: this points also out the importance of coherence and consistency of data with statistical assumptions of the methods employed.

\subsection{Relapses for E-Learning}

Thanks to the wide employment of Felder Silverman learning style model relapses in e-learning can be foreseen, especially for improving student 
modelling in e-learning systems. The results of our study can be used to improve the identification of learning styles. With a more accurate representation of the learning styles of students, e-learning systems can provide more suitable content as well as a personalized sequence of learning objects according to the respective preferences. But providing proper adaptivity is only possible if the learning styles are identified correctly.

The model can be immediately applied for learners' profiling using a suitable distance or proximity measures. Moreover, according to the classification of adaptive hypermedia given by Brusilovsky (Brusilovsky, 20OI), that includes adaptive presentation on one side, and adaptive support navigation on the other, it can be argued that the data driven model can be helpful for developing adaptive and personalized applications according to both these dimensions. In particular, the latent dimensions detected by the model concern the materials, the learning strategies, the kind of contents and tools, and the channels preferred by learners. As an example, adaptation regarding learning styles might include recommendations about multiple media, the sequences of learning materials according to a bottom up or a top down approach, the use of exercises and activities. Additionaly it might include the personalized recommendation of collaborative tools.

\section{CONCLUSIONS AND FUTURE WORK}

In this paper, a data-driven analysis of the relationships between the learning styles of the ILS questionnaire is presented. The outcome leads to some unexpected results that have been analysed and compared with other analyses (Zywno, 2003; Litzinger, Lee \& Wise, 2005; Felder \& Spurlin, 2005).

Looking at the results of this study, it seems reasonable to conclude that learning styles identified by ILS present consistent dependencies between some styles, that the analysis of pairwise coupled dimensions is not able to detect. This leads to suggest that ILS questionnaire assesses dimensions that are not unidimensional, but rather bidimensional and also to conclude for a scarce validity and reliability of ILS questionnaire. While, in order to accept the hypothesis, deeper and appropriate tests are needed, the effectiveness of data-driven approaches, as well as the importance of a knowledge representation coherent and consistent with mathematical and statistical assumptions required by methods employed is pointed out. In particular, it is shown the importance of the whole data analysis process for effective, accurate, and precise models both for applications and for research.

Future work will deal with an in depth investigation and a comparison of these results with datadriven approaches based on usage data analysis for learning style detection, as in (Graf \& Kinshuk, 2006b) and with other investigations concerning the strenght of preferences of styles provided by ILS.

\section{ACKNOWLEDGMENTS}

Silvia Rita Viola would like to acknowledge her teacher Carlo Marchesi. We also would like to thank Tony Holleman from Massey University, New Zealand, for his help in collecting a major part of the data on which our study is based. Also we would like to thank all students who participated and filled out the questionnaire.

This research is curiosity driven, and has been partly funded by the Austrian Federal Ministry for Education, Science, and Culture, and the European Social Fund (ESF) under grant 31.963/46$\mathrm{VII} / 9 / 2002$.

\section{REFERENCES}

Agresti, A. (2002) Categorical Data Analysis. Wiley Interscience, NY, and Edition.

Aitchison, J. (I986) The Statistical Analysis of Compositional Data. Chapman and Hall, London

Brusilovsky, P. (200I) Adaptive Hypermedia. User Modelling and User-Adapted Interaction, $\mathrm{II}(\mathrm{I} / 2)$, pp. 87-IIO

Carver, C. A., Howard, R. A. and Lane, W. D. (I999). Addressing different learning styles through course hypermedia. IEEE Transactions on Education, 42(I), pp. $33-38$.

Cha, H. J., Kim, Y. S., Park, S. H., Yoon, T. B., Jung, Y. M. and Lee, J.-H. (2006). Learning Style Diagnosis Based on User Interface Behavior for the Customization of Learning Interfaces in an Intelligent Tutoring System. In M. Ikeda, K. D. Ashley and T.-W. Chan (Eds.), Proceedings of the 8th International Conference on Intelligent Tutoring Systems, LNCS Vol. 4053, pp. 513-524, Springer-Verlag.

Cherkassky, V. and Mulier, P. (1998) Learning from data. Wiley Interscience, New York.

Cronbach, L. J. (I95I) Coefficient alpha and the internal structure of tests. Psychometrica, I6, pp. 297-333.

Draper, S. (1996) Observing, Measuring and Evaluating a Courseware: a Conceptual Introduction. In Stoner G. (Ed.), Implementing Learning Technology, Available at http://www.icbl.hw.ac.uk/ltdi/implementingit/contacro.htm (retrieved October, 2006) pp. 58-65.

Felder, R. M. and Silverman, L. K. (I988) Learning and 
Teaching Styles in Engineering Education. Engineering Education 78(7), pp. 674-681, Available online

at http://www.ncsu.edu/felderpublic/Papers/LS-I988.pdf (retrieved October, 2006).

Felder, R. M. and Soloman, L. K. (I997) Index of Learning Styles Questionnaire. Online version http://www.engr.ncsu.edu/learningstyles/ ilsweb.html (retrieved October, 2006).

Felder, R. M. and Spurlin, J. (2005) Applications, Reliability and Validity of the Index of Learning Styles. Int. F. on Engineering Education $2 \mathrm{I}(\mathrm{I})$, pp. IO3-II2.

García, P., Amandi, A., Schiaffino, S. and Campo, M. (2006). Evaluating Bayesian networks' precision for detecting students' learning styles. Computers and Education, in press.

Graf, S. and Kinshuk (2006a) An Approach for detecting Learning Styles in Learning Management Systems. In Proceedings of ICALT 2006, 6th IEEE Int. Conf. on Advanced Learning Technologies (ICALT 2006), IEEE Press, Los Alamitos, pp. I6I-I63.

Graf, S. and Kinshuk (2006b). Considering Learning Styles in Learning Management Systems: Investigating the Behavior of Students in an Online Course. In Proceedings of the First IEEE International Workshop on Semantic Media Adaptation and Personalization (SMAP o6), IEEE Press, pp. 25-30.

Graf, S., Viola, S. R., Kinshuk and Leo T. (2006) Representative Characteristics of Felder-Silverman Learning Styles: an empirical model. In Proceedings of CELDA 2006, IADIS Int. Conf. on Cognition and Exploratory Learning in Digital Age.

Greenacre, M. (1984) Theory and Applications of Correspondence Analysis. Academic Press, London.

Hill, T. and Lewicki, P. (2006) STATISTICS. Methods and Applications. Tulsa, OK StatSoft. Also available online at http://www.statsoft.com/textbook/stathome.html (retrieved October, 2006)

Honey, P. and Mumford, A. (1982). The manual of Learning Styles. Maidenhead: Peter Honey.

Jolliffe, T. I. (1986) Principal Component Analysis. Springer, Berlin.

Kolb, D. A. (1984). Experiential Learning: Experience as the Source of Learning and Development. Englewood Cliffs, New Jersey: Prentice-Hall.
Lebart, L., Morineau, M. and Warwick, K. M. (1984) Multivariate Descriptive Statistical Analysis. Wiley Interscience, New York.

Litzinger, T. A., Lee, S. H., and Wise, J. C. (2005) A Study of the Reliability and Validity of the FelderSolomon Index of Learning Styles. In Proceedings of the 2005 American Society for Engineering Annual Conference and Exposition. Available at http://www.ncsu.edu /felder-public/ILSdir/Litzinger_Validation_Study. pdf (retrieved October, 2006).

Papanikolaou, K. A. and Grigoriadou, M. (2003). An Instructional Framework Supporting Personalized Learning on the Web. In Proceedings of the 3 rd IEEE Int. Conf. on Advanced Learning Technologies (ICALT 2003), IEEE Press, Los Alamitos, CA, pp. I2O-I24.

Pearson, K. (I90I) On the Correlation of Characters Not Quantitatively Measurable. Philosophical Transactions of the Royal Statistical Society, 195, pp. I-47.

Peña, C. I., Marzo, J. L. and De la Rosa, J. L. (2002). Intelligent Agents in a Teaching and Learning Environment on the Web. In Proceedings of the 2nd IEEE Int. Conf. on Advanced Learning Technologies (ICALT 2002), Los Alamitos, CA, IEEE Press.

Shang, Y., Shi, H. and Chen, S.-S. (200I). An Intelligent Distributed Environment for Active Learning. ACM Fournal of Educational Resources in Computing, I(2), pp. I-I7.

Siegel, S. and Castellan, N. J. (I988) Nonparametric Statistics for the Behavioural Sciences. McGraw Hill, New York.

Stevens, S. S. (1946) On the theory of scales of measurement. Science I03, pp. 677-680.

Wilkinson, L. (I999) The Grammar of Graphics. Springer, Berlin.

Yule, G. U. (I9I2) On The Methods of Measuring Association Between Two Attributes. F. of the Royal Statistical Society, 75(6), pp. 579-652.

Zywno, M. S. (2003) A Contribution to Validation of Score Meaning for Felder-Soloman's Index of Learning Styles. In Proceedings of the 2003 American Society for Engineering Annual Conference and Exposition. Available online at http://www.ncsu.edu/felder-public/ILSdir/Zywno_Validation_Study.pdf (retrieved October, 2006).

Silvia Rita Viola was born in 1976. In 2001 she graduated in Philosophy at the University of Pisa. On February, 2006 she get the PhD in "E-Learning" at the Universita' Politecnica delle Marche, Ancona, IT. Her research interests are in mathematical models of the WWW data, learning process characterization by data driven approaches and mathematical bioengineering modelling. She is currently with the Universita' Politecnica delle Marche, IT as Research Associate and with the University for Foreigners, IT, as Lecturer for the Course of "Knowledge Engineering".

Sabine Graf is graduate researcher at Women's Postgraduate College for Internet Technologies at Vienna University of Technology, Austria. She is also researcher at Advanced Learning Technology Research Centre of Massey University, New Zealand. Her research interests include adaptivity in web-based educational systems, student modelling, and artificial intelligence.

Kinshuk joined Athabasca University in August 2006 as the Professor and Director of School of Computing and Information Systems. Before moving to Canada, Kinshuk worked at German National Research Centre for Information Technology as Postgraduate Fellow, and at Massey University, New Zealand as Associate Professor of Information Systems and Director of Advanced Learning Technology Research Centre. He also holds Honorary Senior E-Learning Consultant position with Online Learning Systems Ltd., New Zealand, and Docent position with University of Joensuu, Finland. He has been involved in large-scale research projects for exploration based adap- 
Viola et al: Investigating relationships with the index of learning styles

tive educational environments and has published extensively in international refereed journals, conferences and book chapters. He is Chair of IEEE Technical Committee on Learning Technology and International Forum of Educational Technology \& Society. He is also editor of the SSCl indexed Journal of Educational Technology \& Society (ISSN 1436-4522).

Tommaso Leo, born in 1944, is since 1981 Full Professor at the Chair of Automatic Control-Ancona University. He is Author and coauthor of more than 200 papers, editor of some books and special issues in Journals. He is Member of several scientific societies. He has been involved in several National and International Research funded programs. His research interests are in Analysis and Modelling of Human Motor Behaviour, in Measurement Systems and Techniques, in Signal Processing and Optimal Filtering, in Adaptive Control and System Identification, in Friendly Interfaces in biomedicine, in web-based applications for Learning and accreditation, in assistive Robotics. 